\title{
Adapting Cognitive-Behavior Therapy for Insomnia in Cancer Patients
}

\author{
Eric S. Zhou, $\mathrm{PhD}^{1,2}$, Sooyeon Suh, $\mathrm{PhD}^{3}$, Soyoung Youn, $\mathrm{MD}^{4}$, Seockhoon Chung, $\mathrm{MD}, \mathrm{PhD}^{4}$ \\ 'Department of Pediatrics, Harvard Medical School, Boston, MA, USA \\ 'Perini Family Survivors' Center, Dana-Farber Cancer Institute, Boston, MA, USA \\ ${ }^{3}$ Department of Psychology, Sungshin Women's University, Seoul, Korea \\ ${ }^{4}$ Department of Psychiatry, University of Ulsan College of Medicine, Seoul, Korea
}

Received: October 28, 2017

Accepted: November 14, 2017

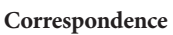

Correspondence

Eric S. Zhou, $\mathrm{PhD}$

Department of Pediatrics,

Harvard Medical School,

450 Brookline Avenue, Boston,

MA 02130, USA

Tel +1-617-632-6162

Fax +1-617-632-2473

E-mail eric_zhou@dfci.harvard.edu

ORCID

Eric S. Zhou

https://orcid.org/0000-0003-1038-8961

Sooyeon Suh

https://orcid.org/0000-0003-0644-8634

Soyoung Youn

https://orcid.org/0000-0003-4983-4017

Seockhoon Chung

https://orcid.org/0000-0002-9798-3642
Insomnia disorder is common in patients undergoing cancer treatment. There is compelling evidence demonstrating that cognitive-behavioral therapy for insomnia (CBT-I) should be the initial treatment, but there has been insufficient research has been conducted among cancer patients. This population presents with unique physical and psychosocial health issues that may interfere with standard CBT-I and addressing these issues can play a role in improving treatment adherence and efficacy. We explore potential adaptations that can be made to standard CBT-I for cancer patients. Further research for this growing population is essential.

Sleep Med Res 2017;8(2):51-61

Key Words Insomnia disorder, Cognitive behavioral therapy for insomnia, Sleep, Cancer patient, Supportive care.

\section{INTRODUCTION}

Insomnia is characterized by difficulty falling asleep and/or staying asleep, resulting in daytime distress/dysfunction. ${ }^{1}$ Among cancer patients receiving active treatment, insomnia is highly prevalent: it is estimated that upwards of $60 \%$ of patients experience insomnia symptoms, with over $25 \%$ meeting diagnostic criteria for insomnia disorder. ${ }^{2-4}$ Insomnia that develops during cancer treatment is unlikely to remit over time. Evidence suggests that years after completing treatment, over $50 \%$ of cancer survivors continue to experience insomnia symptoms, with over $20 \%$ reporting clinically elevated symptoms. ${ }^{5-8}$ Given the known physical and psychological health consequences of insomnia, ${ }^{9-11}$ early identification and treatment of insomnia must be a clinical priority. ${ }^{12}$ Taking a proactive approach to treating insomnia as close to its development as possible is important to minimizing the known impact of poor sleep on the health of cancer patients. ${ }^{3,13,14}$

\section{DEVELOPMENT OF INSOMNIA IN CANCER PATIENTS}

Spielman's 3-P model is widely accepted for explaining the etiology and maintenance processes of chronic insomnia. ${ }^{15}$ The model describes the predisposing, precipitating, and perpetuating factors for insomnia. Predisposing factors are biological or psychological factors that make an individual more likely to develop insomnia, such as female gender, or a family history of insomnia. Precipitating factors are the various triggering factors for acute insomnia, including an environmental or psychological stressor, acute illness, or medication side effects. Once insomnia disorder has developed, it can develop into chronic insomnia through maintenance by perpetuating factors, even though the factors that initially precipitated the sleep disrup- 
tions have diminished or disappeared. Some examples of perpetuating factors include maladaptive sleep behaviors, dysfunctional beliefs and thoughts, or excessive worries. The 3-P model is helpful not only to understand the etiology and maintenance of insomnia, but can also help to identify appropriate targets for proper treatment.

Patients with cancer are exposed to a myriad of precipitating factors for insomnia along the cancer trajectory (Table 1). ${ }^{16} \mathrm{At}$ the outset, a cancer diagnosis itself is a traumatic event that completely alters the course of the patient's life ${ }^{17}$ and can precipitate insomnia. ${ }^{18}$ Following diagnosis, typical cancer treatments including surgery, chemotherapy, radiation therapy, or hormone therapy are often intensive. The physical side effects and psychological distress associated with coping with these health changes during and following treatment can cause the development of insomnia. ${ }^{19-21}$ Furthermore, medications used to manage treatment side effects (e.g., pain), and co-morbid medical disorders can independently cause insomnia. It is important to also recognize that cancer treatment occurs in an individual who will present with pre-existing psychosocial and health morbidities that can affect sleep. For example, the patient may have already been struggling with depression before their cancer diagnosis and treatment, which is known to impair sleep., ${ }^{3,12,14,22-24}$ Patients with cancer may have a problem handling their acute insomnia symptoms not only because of fatigue or disrupted circadian rhythms that accompany with cancer treatment, but also because they are overly concerned about the negative impact of

Table 1. The 3-P model for insomnia among cancer patients ${ }^{8}$

\begin{tabular}{ll}
\hline Predisposing & Older age \\
factors & Female gender \\
& Personal or family history of psychiatric disorder \\
& Medical or psychiatric comorbidities \\
& Hyperarousability trait \\
Precipitating & Distress from cancer diagnosis and treatment \\
factors & Psychiatric symptoms (depression, anxiety, \\
& delirium) \\
& Cancer related symptoms (pain, fatigue, \\
& hot flashes) \\
& Cancer treatment (chemotherapy, radiotherapy, \\
& hormonal therapy) \\
& Certain medications \\
& Surgery or hospitalization \\
& Daytime napping \\
Perpetuating & Excessive time in bed \\
factors & Irregular sleep-wake schedule \\
& Sleep interfering activities (watching smartphone \\
& or TV in bed) \\
& Unrealistic sleep expectations \\
& Faulty sleep appraisals \\
& Tendency to worry in bed \\
\hline
\end{tabular}

insomnia on their health. Dysfunctional beliefs and thoughts can cause excessive fear and anxiety about insomnia, which ultimately lead to maladaptive behaviors such as spending too much time in bed to sleep more, habitual nap, or activities other than sleeping in bed. ${ }^{8,25,26}$ In addition, relationship dysfunction between partners may become exacerbated following a cancer diagnosis, ${ }^{27,28}$ which can impact sleep. Finally, environmental disruptions occur frequently during the cancer treatment (e.g., medical procedures or increased noise during hospitalizations) which interrupt sleep.

It is essential to note that though cancer and its associated treatments can precipitate insomnia, it is not always the case. Nearly $15 \%$ of patients had their first insomnia experience following cancer treatment, ${ }^{2} 58 \%$ reported that cancer aggravated existing sleep problems. ${ }^{18}$ This indicates that insomnia may have been a pre-existing morbidity that now necessitates treatment because the patient's health has been further compromised by cancer and its associated therapies.

\section{INSOMNIA TREATMENT IN CANCER PATIENTS}

Despite known side effects, a goal of short-term use, and potential for interactions with cancer-directed therapies, ${ }^{29-32}$ prescription and over-the-counter medications for insomnia are likely to be the most commonly dispensed form of treatment. Estimates vary, with between $20-50 \%$ of cancer patients taking some form of pharmacotherapy for their sleep problems. ${ }^{33-35}$ This is unfortunate because cognitive-behavioral therapy for insomnia (CBT-I) is a non-pharmacological treatment for insomnia that is endorsed by the National Institutes of Health, American Academy of Sleep Medicine, and the American College of Physicians as the first line of treatment for adults with chronic insomnia. ${ }^{36-39}$ This gap between the best evidence-based care, with actual clinical practice suggests that cancer centers must consider how to better screen for insomnia, and to provide adequate treatment opportunities for their patients. ${ }^{40}$

\section{COGNITIVE-BEHAVIORAL THERAPY FOR INSOMNIA}

\section{General Principles}

CBT-I uses basic behavioral principles and conceptualization of insomnia disorder based on the 3-P model by resolving the perpetuating factors associated with maintaining insomnia, and relearning sleep behaviors that are more conducive to sleep. CBT-I is a short intervention that usually consists of 4-8 weekly sessions and is usually delivered as a multi-component treatment that includes sleep hygiene, stimulus control, sleep restriction, cognitive therapy, and relaxation training. ${ }^{41}$ Currently, stimulus 
control, sleep restriction, and cognitive therapy have been recognized as being effective treatments independently as standalone treatments for insomnia, while sleep hygiene and relaxation training are often considered adjunctive interventions. ${ }^{41}$

While CBT-I is usually divided into behavioral and cognitive components, a recent dismantling study compared full CBT-I, behavioral, and cognitive therapy found that while full CBT-I is the treatment of choice for treatment response and remission rates, both behavior therapy and cognitive therapy were effective. ${ }^{42}$ However, behavior therapy produced rapid effects but did not sustain treatment effects, while cognitive therapy produced slower therapeutic effects, but was more helpful in maintaining treatment effects.

\section{CBT-I Trials in Cancer Populations}

There is growing evidence that CBT-I is an effective treatment for reducing insomnia in cancer patients and survivors, regardless of cancer types, with breast cancer patients accumulating the most evidence to date in treatment response. ${ }^{43-45}$ Traditional face-to-face CBT-I has been compared to self-help CBTI, treatment as usual, mindfulness-based treatment, acupuncture, pharmacotherapy, Tai-Chi, behavior placebo treatment and control conditions in cancer patients. ${ }^{46-48}$ For a more comprehensive review, see Garland et al. ${ }^{49}$ and Johnson et al..$^{50}$ Table 2 is a summary of studies that have used CBT-I in cancer patients.

Studies in CBT-I for cancer patients have also yielded interesting secondary outcomes by improving sleep. While the results have been mixed, several studies have found psychological improvements in mood, such as anxiety, depression, stress. ${ }^{44,51,52}$ Additionally, there has also been some evidence for improvements in fatigue and quality of life. ${ }^{44,52,53}$ There has also been one study by Savard et al. ${ }^{54}$ that have reported on improving physical outcomes. This study found that breast cancer patients treated with CBT-I also had improvements in immune functioning, with increases in interferon (IFN)-gamma, interleukin-1beta, with significant changes in white blood count, lymphocytes, and IFN-gamma also found in follow-up assessments after posttreatment.

\section{ADAPTING COGNITIVE-BEHAVIORAL THERAPY FOR INSOMNIA IN CANCER PATIENTS}

\section{Introduction}

While the accumulating data for CBT-I in improving sleep and other psychological and physical domains looks promising, there appears to be several areas that require further attention. First, there appears to be significant participant drop-out in CBT-I trials conducted among cancer populations. The behavioral changes required of patients undergoing CBT-I would be difficult even in a healthy adult and when coupled with on- going cancer-related issues, can seem insurmountable. Across 25 studies, drop-out rates ranged from $6.2-56.3 \%$, with an average of approximately 1 in 5 participants prematurely terminating treatment. While there have been no studies of predictors of drop-out in CBT-I patients with cancer, a study by Ong et al. $^{55}$ about predictors of drop-out in the general population reported that having an average total sleep time of $<3.65$ hours and depression scores of greater or higher than 16 on the Beck Depression Inventory at baseline were predictors of early treatment termination. Considering these variables, it will be important to identify predictors of adherence or drop-out to enhance treatment effects. Additionally, most of the studies to date that have investigated CBT-I in cancer patients have used a standardized manual developed for insomnia patients, without tailoring specifically to the cancer population. Several additional improvements, such as including CBT-I components in existing psychosocial interventions for cancer patients to deliver a more comprehensive treatment package that specifically address psychological symptoms of cancer, or developing CBT-I manuals to specifically address challenges that are often reported in cancer patients that are associated with sleep, may be able increase treatment effects as well as improve overall quality of life in the long-term in cancer patients and survivors.

\section{Sleep Restriction}

Sleep efficiency commonly guides the treatment of insomnia and describes the ratio of total sleep time compared to time spent in bed. High sleep efficiency is ideal, with a sleep efficiency of at least $85-90 \%$ often used as a marker for good sleep. Longer time spent in bed awake (without associated increases in sleep) will decrease sleep efficiency, so the first step in consolidating sleep during CBT-I is restricting time in bed. Sleep restriction therapy requires placing an initial limit on the amount of time permitted in bed, with the goal of helping patients reduce sleep onset latency and wake after sleep onset by increasing their homeostatic drive for sleep. ${ }^{56}$ The patient's sleep outcomes are usually tracked using daily sleep diaries, ${ }^{57}$ with relevant terms seen in Table 3. This CBT-I component often proves difficult for patients because of the initial, brief period of sleep deprivation that occurs. Patients with cancer can struggle even more as they frequently suffer from symptoms of fatigue related to their cancer-directed therapies (e.g., chemotherapy, radiotherapy), or the cancer itself, which results in physical, emotional, and cognitive tiredness or exhaustion. ${ }^{58}$ The prevalence of cancer-related fatigue is high, ${ }^{59}$ thus it is essential to incorporate a discussion of how to address this in the context of sleep restriction for cancer patients prepare strategies for reducing cancer-related fatigue and providing patients with treatment rationale and sleep education when implementing sleep restriction. For example, patients may report that they are simply too exhausted following a course of treatment to be able to remain awake until their adjusted bedtime. It may be necessary to relax the sleep 


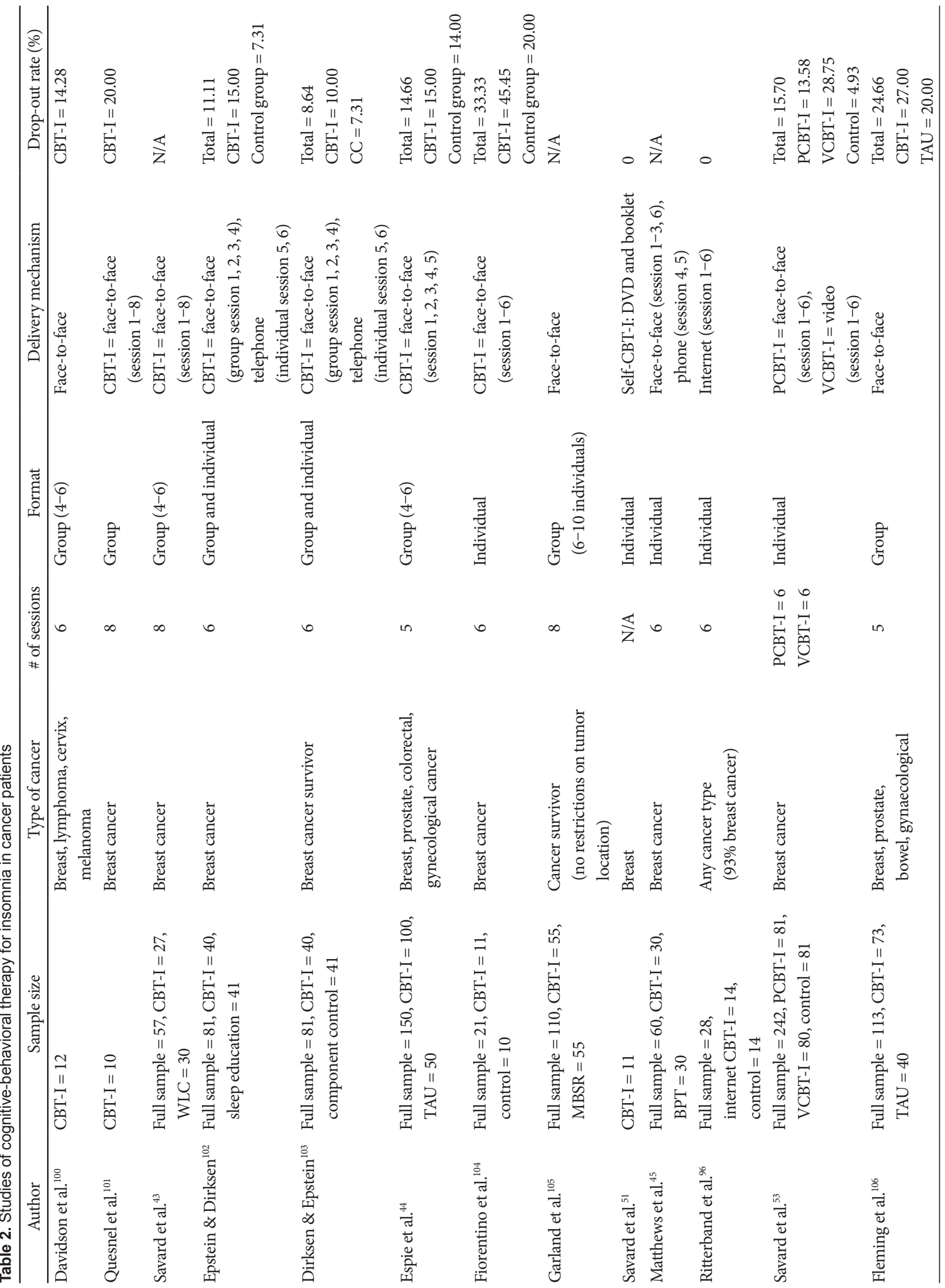




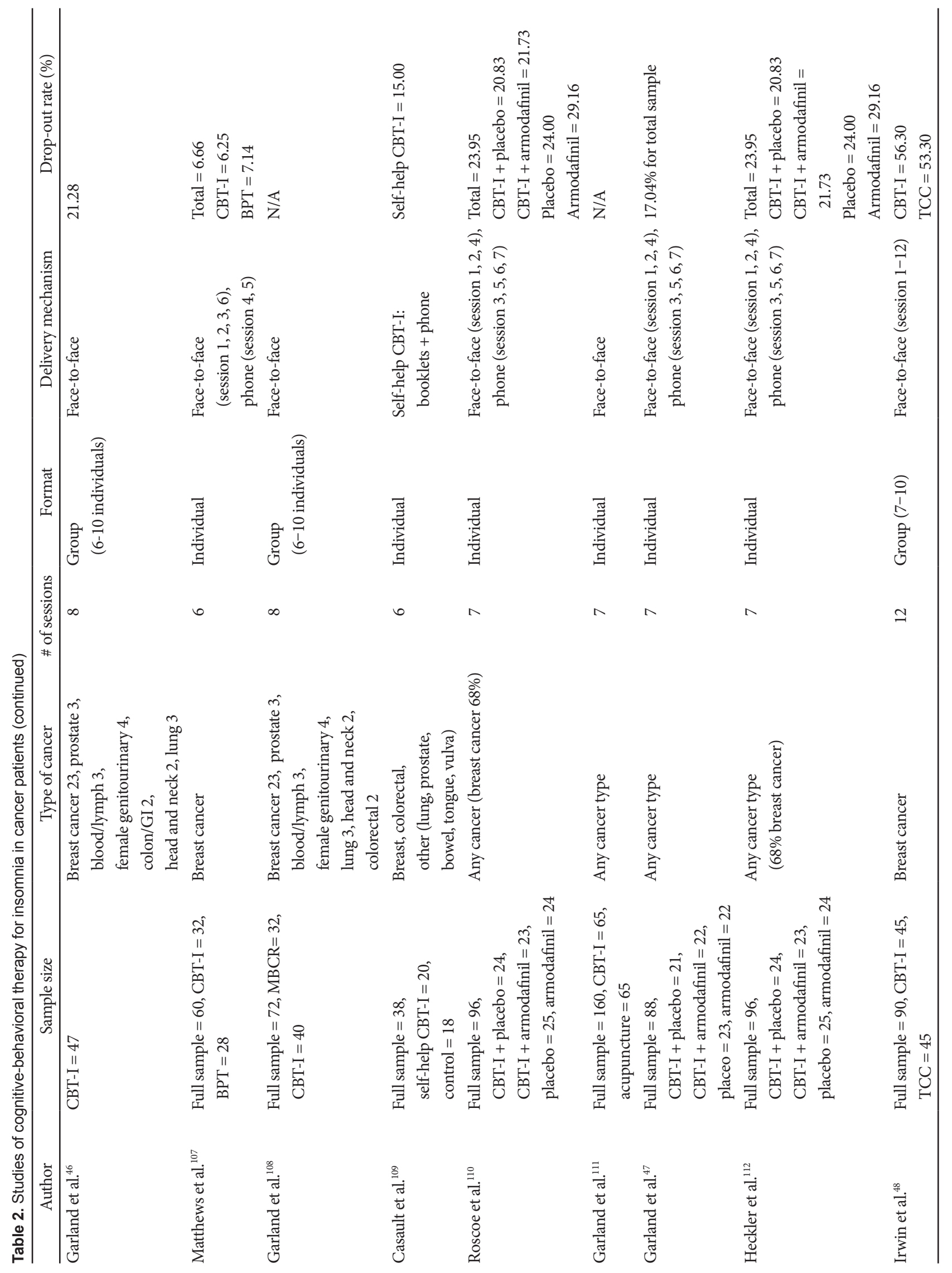




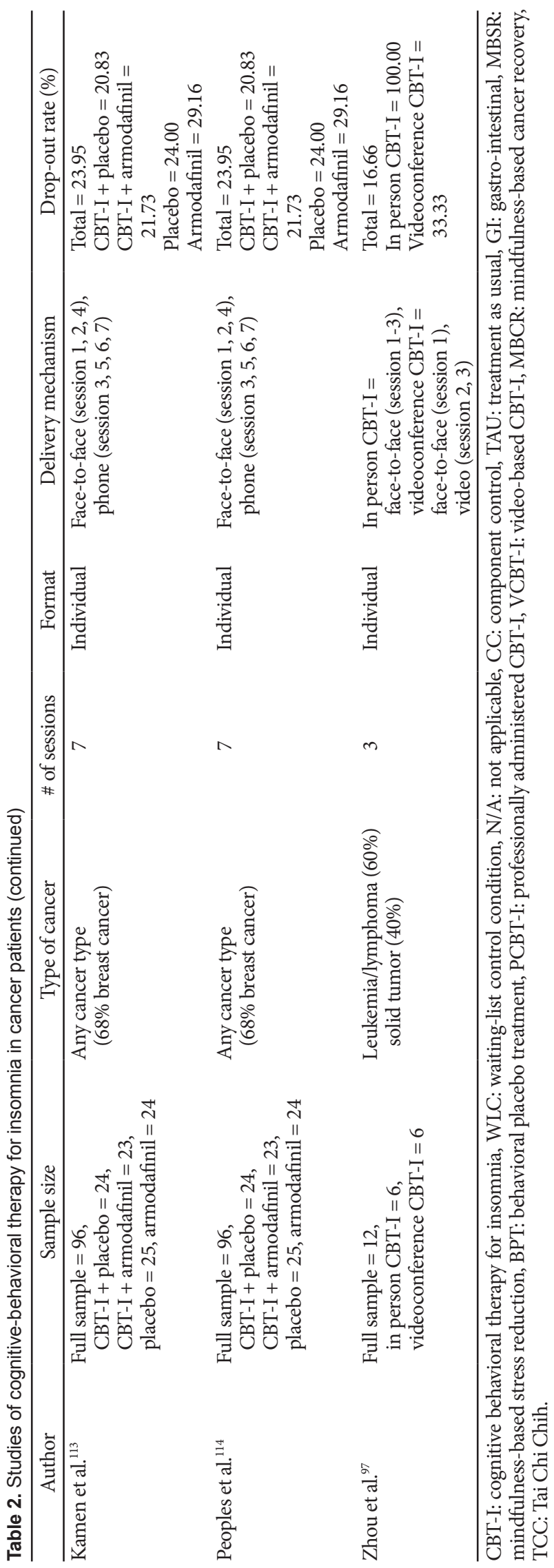

restriction schedule for some patients who cannot comply with their prescribed sleep window, for physical or psychological reasons (or both). Alternatively, a more gradual restriction of time in bed (known as sleep compression) can also be utilized as a therapeutic alternative to sleep restriction for patients who have high anxiety about making drastic changes to their time spent in bed. ${ }^{60}$ Alternatively, it may be wise to determine a period of time during their treatment cycle to initiate treatment as that window of opportunity may provide a clinician with the best chances for success. This all requires a careful discussion with the patient to ensure that the adapted sleep schedule is not simply bending to a common, but inaccurate, view that brief sleep restriction is impossible and/or harmful. Further, for some patients, their efforts at improving sleep may simultaneously present a unique opportunity to also work on improving fatigue outcomes given the overlap in symptom presentation. ${ }^{61,62}$

\section{Stimulus Control}

The basis for stimulus control therapy is the notion that the patient's bed is no longer an effective discriminative stimulus for sleep onset and/or maintenance because it has consistently been associated with other activities in bed. ${ }^{63}$ For example, a patient who cannot sleep may lay in bed on their cell phone, watching television, or simply be trying to get back to sleep by laying still. The approach to addressing this is to inform patients that they can only use their bed for sleep (and sexual activity), but must leave the bed if they are unable to sleep for a pre-determined duration (e.g., 15 minutes) ${ }^{64}$ Stimulus control has been demonstrated to be effective by itself as a treatment for insomnia in adults. ${ }^{65}$ This can be a difficult portion of treatment to implement for a cancer patient. During hospitalizations, and even in outpatient care, they have often been instructed to remain in bed (or on a couch) by their providers in order to 'get as much rest as possible.' This often occurs during the daytime, with napping a common occurrence, and disruptions to a healthy sleep/wake schedule may influence their sleep onset, maintenance, and quality of sleep in the evening. ${ }^{66} \mathrm{~A}$ thoughtful discussion with the patient focused on their inaccurate perceptions of benefits accrued by spending an excessive amount of time in bed not sleeping, and the potential improvements should they get out of bed, can be helpful. It is also reasonable to gently remind the patient that their pattern of spending time in bed has not resulted in improvements to their daytime function or nighttime sleep. Helping the patient identify pleasurable activities to distract them in the late evening/early morning when they are unable to sleep and must remain out of their bed is essential to success. The enlistment of a partner, family member, or friend's support can be crucial.

\section{Cognitive Therapy}

The cognitive therapy component of CBT-I applies traditional techniques of cognitive therapy developed by Beck and 
Table 3. Sleep indices to explore individual's sleep structure

\begin{tabular}{clc}
\hline Abbreviation & \multicolumn{1}{c}{ Sleep index } & Definition \\
\hline SOL & Sleep onset latency & $20,30,45$ minutes \\
TIB & Time in bed & 7 hours: 11 pm-6 am \\
TIB/d ${ }^{115}$ & Time in bed during 24 hours & $7-8$ hours \\
TST & Total sleep time & $7-8$ hours \\
SE & Sleep efficiency & $85,90 \%$ \\
WASO & Wake after sleep onset & $20,30,45$ minutes \\
PTB $^{116}$ & Duration from administration of pills to bedtime & $<30$ minutes \\
PTS $^{116}$ & Duration from administration of pills to sleep onset time & $<30$ minutes \\
PTW $^{116}$ & Duration from administration of pills to wake up time & $7-8$ hours \\
\hline
\end{tabular}

colleagues ${ }^{67,68}$ in challenging and restructuring maladaptive and dysfunctional beliefs and attitudes that maintain insomnia. The main purpose of cognitive therapy is to modify the following beliefs: 1) unrealistic expectations about sleep needs and daytime functioning, 2) misattributions about the causes of insomnia, 3) catastrophizing the effects of the consequences of insomnia, and 4) dysfunctional beliefs about ways to improve sleep. Additionally, it is often helpful to discuss coping strategies to help the patient manage the negative daytime effects of insomnia. Cognitive therapy techniques can be utilized in different ways. Oftentimes, an adjunctive questionnaire such as the Dysfunctional Beliefs and Attitudes about Sleep Scale ${ }^{69}$ or Glasgow Contents of Thoughts Inventory ${ }^{70}$ is used to understand the nature and content of thoughts associated with insomnia. Some therapists use a daily mood log that patients can use in-session and for homework that identifies specific situations associated with sleep, automatic thoughts, and emotions associated with the automatic thoughts. Classical Socratic questioning techniques can be used in session to elicit more adaptive and realistic cognitions to replace the dysfunctional beliefs associated with sleep, and behavioral experiments can be used to challenge faulty thinking. Ultimately, the patient becomes practiced at identifying their cognitive distortions and maladaptive thoughts associated with sleep, and becomes able to modify their thoughts without the help of a therapist.

There are several distinctive dysfunctional beliefs about sleep that cancer patients may report, such as 'Not going to sleep at a certain time will have a serious effect on my immune system' or 'If I do not sleep well at night, my cancer may recur or metastasize.71 ${ }^{71}$ o some degree, these concerns may have some merit. $^{72}$ The former is supported by the fact that melatonin affects immunity, and it is also true that melatonin is secreted more at a certain time. ${ }^{73}$ In the latter case, there are also several studies reporting associations between cancer incidence and mortality, with sleep duration. ${ }^{74-76}$ However, cancer patients may be exposed to this information repeatedly through mass media, which may result in exaggerated and distorted dysfunctional beliefs about these consequences of poor sleep. Worrying about sleep may in fact cause additional stress, which may subsequently have a deleterious effect on their health. In fact, it has been demonstrated that stress reactions related with excessive anxiety and fear may increase cortisol levels, which affects one's immune system. ${ }^{77,78}$ In addition, these negative emotional states can exacerbate insomnia symptoms. Thus, when applying cognitive therapy to patients with cancer, it is important to help the patient understand that avoiding repeatedly thinking about the consequences of insomnia is the best way to break the vicious cycle and sleep well. This can be particularly important during the sleep restriction phase of CBT-I, where it is helpful to explain to patients that this brief period of poor sleep is unlikely to cause enduring health consequences, and in fact, is likely to improve their function in the long-term.

\section{Sleep Hygiene}

The term "sleep hygiene" refers to behaviors that promote improved quantity and quality of sleep. ${ }^{79}$ There lacks a clear consensus as to what specifically comprises sleep hygiene, though these rules are generally guided by the overarching principles to avoid sleep interfering behaviors and to increase sleep promotion behaviors. Examples of sleep hygiene principles include: 1) decreasing time in bed, 2) regular bed/wake times, 3) exercise, 4) eliminate bedroom noise, 5) regulate bedroom temperature, 6) light snack at bedtime, 7) avoid caffeine/alcohol consumption, 8) eliminate bedroom clock, and 9) relaxing activities before bed. ${ }^{80}$ The American Academy of Sleep Medicine recommends sleep hygiene education as a part of treatment of insomnia, ${ }^{39}$ though evidence suggests that sleep hygiene therapy as a single treatment modality for insomnia is likely to be ineffective. This may be due to several factors, such as many patients simply receiving a sleep hygiene handout, without any guidance or support on how and when to implement these strategies, vague and/or inconsistent sleep hygiene instructions. ${ }^{81} \mathrm{~A}$ patient's sleep hygiene behaviors can be explored via a clinical interview, or can be assessed using a questionnaire such as the Sleep Hygiene Index. ${ }^{82}$ There have been several studies which have explored the effectiveness of sleep hygiene on insomnia 
among cancer patients as a single modality, and most studies combined sleep hygiene with relaxation training or other modalities. ${ }^{83,84}$ It is likely that poor sleep hygiene practices can influence insomnia severity, but may not necessarily independently be sufficient to completely resolve symptoms. Several examples of sleep hygiene issues that arise for cancer patients include difficulty with maintaining consistent sleep/wake schedules and daytime napping, which is associated with compromised sleep quality ${ }^{85}$ These sleep hygiene issues may develop during an inpatient hospitalization, especially if patients must share a room with others. ${ }^{86}$ Clinicians working with cancer patients on addressing sleep hygiene concerns must ensure that they engage in a thoughtful conversation about the importance of maintaining proper sleep hygiene, and to set proper expectations that improving sleep hygiene factors is likely to create incremental improvements to sleep rather than completely overhaul how well the patient is sleeping. ${ }^{87}$

\section{Relaxation}

There has been a considerable history of the use of relaxation techniques to the treatment of insomnia. Relaxation approaches have included progressive muscle relaxation, autogenic training, and imagery among others. ${ }^{88-91}$ It does not appear to be as effective as other components of CBT-I (e.g., stimulus control) by itself, ${ }^{92}$ but does promote improved sleep. There is evidence to suggest that relaxation therapy can be a helpful intervention among cancer populations, ${ }^{93}$ with a possible secondary benefit of also improving fatigue. ${ }^{94}$ The use of some relaxation techniques can be challenging for cancer patients. For example, requires the individual to tense their muscles, which can be difficult for some patients following treatment (e.g., surgery). In addition, asking a patient who has never practiced relaxation before to consistently independently perform relaxation exercises is unlikely without some form of structured support. ${ }^{95}$ Discussing which relaxation strategies are suitable for the particular patient and recognizing potential physical limitations and potentially working with other providers (e.g., physical therapist) to ensure they are appropriate can be helpful. In addition, working directly with patients to identify possible barriers to consistent practice of relaxation exercises and trying to find solutions to these issues (i.e., enrollment in group classes at their cancer center) can improve compliance with treatment recommendations.

\section{Intervention Delivery}

Most clinical trials conducted of CBT-I in cancer populations have been performed in-person and have usually remained faithful to the standard protocol of 4-8 sessions..$^{50}$ This has major implications for limiting patient access should they not have the fortune of receiving medical care at a research-focused cancer center where a CBT-I trial is being conducted. Efforts have been undertaken to trial self-help, video, web, and telehealth CBT-I in order to address treatment access barriers, with compelling evidence suggesting that these novel delivery mechanisms can be successful. ${ }^{51,53,96,97}$ However, major challenges remain with respect to adequate screening for insomnia in cancer programs. ${ }^{40}$ In combination with the low likelihood that a patient with insomnia will seek professional treatment, ${ }^{98}$ there remain vital public health and medical provider education training gaps that should be addressed in order to help cancer patients get the evidence-based insomnia treatment that they require.

\section{CONCLUSION}

Insomnia is common along the cancer trajectory, with good reason to believe that it will develop during cancer treatment for a sizable number of patients. In the general, and cancer-survivor populations, there have been many trials which have demonstrated that CBT-I is effective at improving insomnia symptomatology, mood, and quality of life. However, there have been fewer trials which have explored how such an approach can be adapted to respond to the cancer-related issues that are experienced by patients undergoing active cancer-directed therapies. Many of the core CBT-I treatment components may be difficult to fully implement in a patient who is receiving cancer treatment, and compromises are often made in the clinical setting in response to these challenges. The future exploration of how this can occur in a structured approach is necessary. Whether it will be advantageous to embed cancer-related content within standard CBT-I protocols, or if it is advisable to build a separate 'cancer module' to complement existing content, or a combination of these approaches, is an interesting question that researchers have yet to fully address. For the 14+ million patients diagnosed with cancer worldwide every year, ${ }^{99}$ this is a clinically important line of research that must be pursued.

\section{Conflicts of Interest}

The authors have no financial conflicts of interest.

\section{Authors' Contribution}

Conceptualization: Zhou ES, Chung S. Data curation: Suh S. Project administration: Chung S. Writing-original draft: Zhou ES, Suh S, Youn S, Chung S. Writing_-review \& editing: Zhou ES, Suh S, Youn S, Chung S.

\section{REFERENCES}

1. American Psychiatric Association. Diagnostic and Statistical Manual of Mental Disorders, Fifth Edition. Washington: American Psychiatric Association 2013.

2. Savard J, Ivers H, Villa J, Caplette-Gingras A, Morin CM. Natural course of insomnia comorbid with cancer: an 18-month longitudinal study. J Clin Oncol 2011;29:3580-6.

3. Palesh OG, Roscoe JA, Mustian KM, Roth T, Savard J, Ancoli-Israel S, et al. Prevalence, demographics, and psychological associations of sleep disruption in patients with cancer: University of Rochester Cancer Center-community clinical oncology program. J Clin Oncol 2010; 28:292-8. 
4. Park B, Youn S, Hann C-WC, Yi K, Lee S, Lee JS, et al. Prevalence of insomnia among patients with the ten most common cancers in South Korea: health insurance review and assessment service-national patient sample. Sleep Med Res 2016;7:48-54

5. Zhou ES, Recklitis CJ. Insomnia in adult survivors of childhood cancer: a report from project REACH. Support Care Cancer 2014;22:3061-9.

6. Zhou ES, Manley PE, Marcus KJ, Recklitis CJ. Medical and psychosocial correlates of insomnia symptoms in adult survivors of pediatric brain tumors. J Pediatr Psychol 2016;41:623-30.

7. Gooneratne NS, Dean GE, Rogers AE, Nkwuo JE, Coyne JC, Kaiser LR. Sleep and quality of life in long-term lung cancer survivors. Lung Cancer 2007;58:403-10.

8. Savard J, Morin CM. Insomnia in the context of cancer: a review of a neglected problem. J Clin Oncol 2001;19:895-908.

9. Walsh JK, Üstün TB. Prevalence and health consequences of insomnia. Sleep 1999;22:S427-36.

10. Roth T. Insomnia: definition, prevalence, etiology, and consequences. $J$ Clin Sleep Med 2007;3:S7-10.

11. Taylor DJ, Lichstein KL, Durrence HH. Insomnia as a health risk factor. Behav Sleep Med 2003;1:227-47.

12. Fleming L, Gillespie S, Espie CA. The development and impact of insomnia on cancer survivors: a qualitative analysis. Psychooncology 2010;19:991-6.

13. Palesh O, Aldridge-Gerry A, Zeitzer JM, Koopman C, Neri E, Giese-Davis J, et al. Actigraphy-measured sleep disruption as a predictor of survival among women with advanced breast cancer. Sleep 2014;37:83742.

14. Redeker NS, Lev EL, Ruggiero J. Insomnia, fatigue, anxiety, depression, and quality of life of cancer patients undergoing chemotherapy. Sch Inq Nurs Pract 2000;14:275-90; discussion 291-8.

15. Spielman AJ, Caruso LS, Glovinsky PB. A behavioral perspective on insomnia treatment. Psychiatr Clin North Am 1987;10:541-53.

16. Lowery AE. Sleep and cancer. In: Holland JC, Breitbart WS, Butow PN, Jacobsen PB, Loscalzo MJ, McCorkle R. Psycho-Oncology. 3rd ed. New York: Oxford University Press 2015;231.

17. van't Spijker A, Trijsburg RW, Duivenvoorden HJ. Psychological sequelae of cancer diagnosis: a meta-analytical review of 58 studies after 1980. Psychosom Med 1997;59:280-93.

18. Savard J, Simard S, Blanchet J, Ivers H, Morin CM. Prevalence, clinical characteristics, and risk factors for insomnia in the context of breast cancer. Sleep 2001;24:583-90.

19. Savard J, Hervouet S, Ivers H. Prostate cancer treatments and their side effects are associated with increased insomnia. Psychooncology 2013; 22:1381-8

20. Enderlin CA, Coleman EA, Cole C, Richards KC, Hutchins LF, Sherman AC. Sleep across chemotherapy treatment: a growing concern for women older than 50 with breast cancer. Oncol Nurs Forum 2010;37:461-A3.

21. Van Onselen C, Paul SM, Lee K, Dunn L, Aouizerat BE, West C, et al. Trajectories of sleep disturbance and daytime sleepiness in women before and after surgery for breast cancer. J Pain Symptom Manage 2013; 45:244-60.

22. Costa AR, Fontes F, Pereira S, Gonçalves M, Azevedo A, Lunet N. Impact of breast cancer treatments on sleep disturbances-a systematic review. Breast 2014;23:697-709.

23. Rumble ME, Keefe FJ, Edinger JD, Affleck G, Marcom PK, Shaw HS. Contribution of cancer symptoms, dysfunctional sleep related thoughts, and sleep inhibitory behaviors to the insomnia process in breast cancer survivors: a daily process analysis. Sleep 2010;33:1501-9.

24. Ancoli-Israel S. Recognition and treatment of sleep disturbances in cancer. J Clin Oncol 2009;27:5864-6.

25. Woodward SC. Cognitive-behavioral therapy for insomnia in patients with cancer. Clin J Oncol Nurs 2011;15:E42-52.

26. Graci G. Pathogenesis and management of cancer-related insomnia. J Support Oncol 2005;3:349-59.

27. Fergus KD, Gray RE. Relationship vulnerabilities during breast cancer: patient and partner perspectives. Psychooncology 2009;18:1311-22.

28. Holmberg SK, Scott LL, Alexy W, Fife BL. Relationship issues of women with breast cancer. Cancer Nurs 2001;24:53-60.

29. Walsh JK. Pharmacologic management of insomnia. J Clin Psychiatry 2004;65 Suppl 16:41-5.

30. Tariq SH, Pulisetty S. Pharmacotherapy for insomnia. Clin Geriatr Med 2008;24:93-105, vii.

31. Sideras K, Ingle JN, Ames MM, Loprinzi CL, Mrazek DP, Black JL, et al. Coprescription of tamoxifen and medications that inhibit CYP2D6. J Clin Oncol 2010;28:2768-76.

32. Lemmo W. Potential interactions of prescription and over-the-counter medications having antioxidant capabilities with radiation and chemotherapy. Int J Cancer 2015; 137:2525-33.

33. Jaeger H, Morrow GR, Carpenter PJ, Brescia F. A survey of psychotropic drug utilization by patients with advanced neoplastic disease. Gen Hosp Psychiatry 1985;7:353-60.

34. Moore TA, Berger AM, Dizona P. Sleep aid use during and following breast cancer adjuvant chemotherapy. Psychooncology 2011;20:321-5.

35. Casault L, Savard J, Ivers H, Savard MH, Simard S. Utilization of hypnotic medication in the context of cancer: predictors and frequency of use. Support Care Cancer 2012;20:1203-10.

36. National Institutes of Health. National Institutes of Health State of the science conference statement on manifestations and management of chronic insomnia in adults, June 13-15, 2005. Sleep 2005;28:1049-57.

37. Wilson SJ, Nutt DJ, Alford C, Argyropoulos SV, Baldwin DS, Bateson AN, et al. British Association for Psychopharmacology consensus statement on evidence-based treatment of insomnia, parasomnias and circadian rhythm disorders. J Psychopharmacol 2010;24:1577-601.

38. Qaseem A, Kansagara D, Forciea MA, Cooke M, Denberg TD; Clinical Guidelines Committee of the American College of Physicians. Management of chronic insomnia disorder in adults: a clinical practice guideline from the American College of Physicians. Ann Intern Med 2016; 165:125-33.

39. Morgenthaler T, Kramer M, Alessi C, Friedman L, Boehlecke B, Brown T, et al. Practice parameters for the psychological and behavioral treatment of insomnia: an update. An american academy of sleep medicine report. Sleep 2006;29:1415-9.

40. Zhou ES, Partridge AH, Syrjala KL, Michaud AL, Recklitis CJ. Evaluation and treatment of insomnia in adult cancer survivorship programs. J Cancer Surviv 2017;11:74-9.

41. Smith MT, Smith LJ, Nowakowski S, Perlis ML. Primary insomnia: diagnostic issues, treatment, and future directions. In: Perlis ML, Lichstein KL. Treating sleep disorders: principles and practice of behavioral sleep medicine. 1st ed. Hoboken: John Wiley \& Sons, Inc. 2003:214-61.

42. Harvey AG, Bélanger L, Talbot L, Eidelman P, Beaulieu-Bonneau S, Fortier-Brochu É, et al. Comparative efficacy of behavior therapy, cognitive therapy, and cognitive behavior therapy for chronic insomnia: a randomized controlled trial. J Consult Clin Psychol 2014;82:670-83.

43. Savard J, Simard S, Ivers H, Morin CM. Randomized study on the efficacy of cognitive-behavioral therapy for insomnia secondary to breast cancer, part II: Immunologic effects. J Clin Oncol 2005;23:6097-106.

44. Espie CA, Fleming L, Cassidy J, Samuel L, Taylor LM, White CA, et al. Randomized controlled clinical effectiveness trial of cognitive behavior therapy compared with treatment as usual for persistent insomnia in patients with cancer. J Clin Oncol 2008;26:4651-8.

45. Matthews EE, Schmiege SJ, Cook PF, Berger AM, Aloia MS. Adherence to cognitive behavioral therapy for insomnia (CBTI) among women following primary breast cancer treatment: a pilot study. Behav Sleep Med 2012;10:217-29.

46. Garland SN, Carlson LE, Stephens AJ, Antle MC, Samuels C, Campbell TS. Mindfulness-based stress reduction compared with cognitive behavioral therapy for the treatment of insomnia comorbid with cancer: a randomized, partially blinded, noninferiority trial. J Clin Oncol 2014;32:449-57.

47. Garland SN, Roscoe JA, Heckler CE, Barilla H, Gehrman P, Findley 
JC, et al. Effects of armodafinil and cognitive behavior therapy for insomnia on sleep continuity and daytime sleepiness in cancer survivors. Sleep Med 2016;20:18-24.

48. Irwin MR, Olmstead R, Carrillo C, Sadeghi N, Nicassio P, Ganz PA, et al. Tai Chi Chih compared with cognitive behavioral therapy for the treatment of insomnia in survivors of breast cancer: a randomized, partially blinded, noninferiority trial. J Clin Oncol 2017;35:2656-65.

49. Garland SN, Johnson JA, Savard J, Gehrman P, Perlis M, Carlson L, et al. Sleeping well with cancer: a systematic review of cognitive behavioral therapy for insomnia in cancer patients. Neuropsychiatr Dis Treat 2014;10:1113-24.

50. Johnson JA, Rash JA, Campbell TS, Savard J, Gehrman PR, Perlis M, et al. A systematic review and meta-analysis of randomized controlled trials of cognitive behavior therapy for insomnia (CBT-I) in cancer survivors. Sleep Med Rev 2016;27:20-8.

51. Savard J, Villa J, Simard S, Ivers H, Morin CM. Feasibility of a self-help treatment for insomnia comorbid with cancer. Psychooncology 2011; 20:1013-9.

52. Savard J, Simard S, Ivers H, Morin CM. Randomized study on the efficacy of cognitive-behavioral therapy for insomnia secondary to breast cancer, part I: Sleep and psychological effects. J Clin Oncol 2005;23: 6083-96.

53. Savard J, Ivers H, Savard MH, Morin CM. Is a video-based cognitive behavioral therapy for insomnia as efficacious as a professionally administered treatment in breast cancer? Results of a randomized controlled trial. Sleep 2014;37:1305-14.

54. Savard J, Simard S, Giguère I, Ivers H, Morin CM, Maunsell E, et al. Randomized clinical trial on cognitive therapy for depression in women with metastatic breast cancer: psychological and immunological effects. Palliat Support Care 2006;4:219-37.

55. Ong JC, Kuo TF, Manber R. Who is at risk for dropout from group cognitive-behavior therapy for insomnia? J Psychosom Res 2008;64: 419-25.

56. Spielman AJ, Saskin P, Thorpy MJ. Treatment of chronic insomnia by restriction of time in bed. Sleep 1987;10:45-56.

57. Carney CE, Buysse DJ, Ancoli-Israel S, Edinger JD, Krystal AD, Lichstein $\mathrm{KL}$, et al. The consensus sleep diary: standardizing prospective sleep self-monitoring. Sleep 2012;35:287-302.

58. Mock V, Abernathy A, Atkinson A, Barsevick A, Berger A, Cella D. NCCN Clinical Practice Guidelines in Oncology ${ }^{\mathrm{TM}}$. In: Cancer-related fatigue. Washington: National Comprehensive Cancer Network 2015.

59. Cella D, Davis K, Breitbart W, Curt G; Fatigue Coalition. Cancer-related fatigue: prevalence of proposed diagnostic criteria in a United States sample of cancer survivors. J Clin Oncol 2001;19:3385-91.

60. Lichstein KL. Sleep compression treatment of an insomnoid. Behavior Therapy 1988;19:625-32.

61. Berger AM, Kuhn BR, Farr LA, Lynch JC, Agrawal S, Chamberlain J, et al. Behavioral therapy intervention trial to improve sleep quality and cancer-related fatigue. Psychooncology 2009;18:634-46.

62. Kangas M, Bovbjerg DH, Montgomery GH. Cancer-related fatigue: a systematic and meta-analytic review of non-pharmacological therapies for cancer patients. Psychol Bull 2008;134:700-41.

63. Bootzin RR. Stimulus control treatment for insomnia. In: American psychological association. APA 80th Annual Convention. Honolulu: American Psychological Association 1972;1973.

64. Bootzin RR, Epstein D, Wood JM. Stimulus control instructions. In: Hauri PJ. Case studies in insomnia. Boston: Springer 1991;19-28.

65. Puder R, Lacks P, Bertelson AD, Storandt M. Short-term stimulus control treatment of insomnia in older adults. Behavior Therapy 1983;14: 424-9.

66. Ancoli-Israel S, Moore PJ, Jones V. The relationship between fatigue and sleep in cancer patients: a review. Eur J Cancer Care (Engl) 2001;10: 245-55.

67. Beck AT. Cognitive therapy of depression. 2nd ed. New York: Guilford Press 1979.
68. Beck A, Emery G, Greenberg R. Anxiety disorders and phobias: a cognitive perspective. New York: Basic Books 2005.

69. Morin CM, Vallières A, Ivers H. Dysfunctional beliefs and attitudes about sleep (DBAS): validation of a brief version (DBAS-16). Sleep 2007; 30:1547-54.

70. Harvey KJ, Espie CA. Development and preliminary validation of the Glasgow Content of Thoughts Inventory (GCTI): a new measure for the assessment of pre-sleep cognitive activity. Br J Clin Psychol 2004; 43:409-20.

71. Chung S, Youn S, Choi B. Assessment of cancer-related dysfunctional beliefs about sleep for evaluating sleep disturbance in cancer patients. Sleep Med Res 2017 Nov 3 [Epub ahead of print]. https://doi.org/10. 17241/smr.2017.00073.

72. Carrillo-Vico A, Lardone PJ, Alvarez-Sánchez N, Rodríguez-Rodríguez A, Guerrero JM. Melatonin: buffering the immune system. Int $J$ Mol Sci 2013;14:8638-83.

73. Lewy AJ. The dim light melatonin onset, melatonin assays and biological rhythm research in humans. Biol Signals Recept 1999;8:79-83.

74. Jiao L, Duan Z, Sangi-Haghpeykar H, Hale L, White DL, El-Serag HB. Sleep duration and incidence of colorectal cancer in postmenopausal women. Br J Cancer 2013;108:213-21.

75. Trudel-Fitzgerald C, Zhou ES, Poole EM, Zhang X, Michels KB, Eliassen $\mathrm{AH}$, et al. Sleep and survival among women with breast cancer: 30 years of follow-up within the Nurses' Health Study. Br J Cancer 2017;116: 1239-46.

76. Collins KP, Geller DA, Antoni M, Donnell DM, Tsung A, Marsh JW, et al. Sleep duration is associated with survival in advanced cancer patients. Sleep Med 2017;32:208-12.

77. Reiche EM, Nunes SO, Morimoto HK. Stress, depression, the immune system, and cancer. Lancet Oncol 2004;5:617-25.

78. Dettenborn L, James GD, Valdimarsdottir HB, Montgomery GH, Bovbjerg DH. Breast cancer-specific intrusions are associated with increased cortisol responses to daily life stressors in healthy women without personal or family histories of breast cancer. J Behav Med 2006; 29:477-85.

79. Hauri P. The sleep disorders (Current concepts). 2nd ed. Kalamazoo: Upjohn 1982;2-16.

80. Stepanski EJ, Wyatt JK. Use of sleep hygiene in the treatment of insomnia. Sleep Med Rev 2003;7:215-25.

81. Irish LA, Kline CE, Gunn HE, Buysse DJ, Hall MH. The role of sleep hygiene in promoting public health: A review of empirical evidence. Sleep Med Rev 2015;22:23-36.

82. Mastin DF, Bryson J, Corwyn R. Assessment of sleep hygiene using the Sleep Hygiene Index. J Behav Med 2006;29:223-7.

83. Simeit R, Deck R, Conta-Marx B. Sleep management training for cancer patients with insomnia. Support Care Cancer 2004;12:176-83.

84. Zupanec S, Jones H, McRae L, Papaconstantinou E, Weston J, Stremler R. A Sleep hygiene and relaxation intervention for children with acute lymphoblastic leukemia: a pilot randomized controlled trial. Cancer Nurs 2017;40:488-96.

85. Walker AJ, Johnson KP, Miaskowski C, Lee KA, Gedaly-Duff V. Sleep quality and sleep hygiene behaviors of adolescents during chemotherapy. J Clin Sleep Med 2010;6:439-44.

86. Youn S, Hann C-WC, Park B, Lee S, Kim C, Yi K, et al. The sleeping pill prescription rate for inpatients at a general hospital. Sleep Medicine Research 2016;7:33-8.

87. Haynes PL, Bootzin RR. Insomnia treatments: moving from efficacy to effectiveness. J Clin Psychol 2010;66:1131-6.

88. Borkovec TD, Fowles DC. Controlled investigation of the effects of progressive and hypnotic relaxation on insomnia. J Abnorm Psychol 1973; 82:153-8

89. Nicassio P, Bootzin R. A comparison of progressive relaxation and autogenic training as treatments for insomnia. J Abnorm Psychol 1974;83: 253-60.

90. Kahn M, Baker BL, Weiss JM. Treatment of insomnia by relaxation 
training. J Abnorm Psychol 1968;73:556-8.

91. Woolfolk RL, McNulty TF. Relaxation treatment for insomnia: a component analysis. J Consult Clin Psychol 1983;51:495-503.

92. Lacks P, Bertelson AD, Gans L, Kunkel J. The effectiveness of three behavioral treatments for different degrees of sleep onset insomnia. Behavior Therapy 1983;14:593-605.

93. Cannici J, Malcolm R, Peek LA. Treatment of insomnia in cancer patients using muscle relaxation training. J Behav Ther Exp Psychiatry 1983;14:251-6.

94. Demiralp M, Oflaz F, Komurcu S. Effects of relaxation training on sleep quality and fatigue in patients with breast cancer undergoing adjuvant chemotherapy. J Clin Nurs 2010;19:1073-83.

95. Adamsen L, Stage M, Laursen J, Rørth M, Quist M. Exercise and relaxation intervention for patients with advanced lung cancer: a qualitative feasibility study. Scand J Med Sci Sports 2012;22:804-15.

96. Ritterband LM, Bailey ET, Thorndike FP, Lord HR, Farrell-Carnahan L, Baum LD. Initial evaluation of an Internet intervention to improve the sleep of cancer survivors with insomnia. Psychooncology 2012;21: 695-705.

97. Zhou ES, Vrooman LM, Manley PE, Crabtree VM, Recklitis CJ. Adapted delivery of cognitive-behavioral treatment for insomnia in adolescent and young adult cancer survivors: a pilot study. Behav Sleep Med 2017;15:288-301.

98. Morin CM, LeBlanc M, Daley M, Gregoire JP, Mérette C. Epidemiology of insomnia: prevalence, self-help treatments, consultations, and determinants of help-seeking behaviors. Sleep Med 2006;7:123-30.

99. Torre LA, Bray F, Siegel RL, Ferlay J, Lortet-Tieulent J, Jemal A. Global cancer statistics, 2012. CA Cancer J Clin 2015;65:87-108.

100. Davidson JR, Waisberg JL, Brundage MD, MacLean AW. Nonpharmacologic group treatment of insomnia: a preliminary study with cancer survivors. Psychooncology 2001;10:389-97.

101. Quesnel C, Savard J, Simard S, Ivers H, Morin CM. Efficacy of cognitive-behavioral therapy for insomnia in women treated for nonmetastatic breast cancer. J Consult Clin Psychol 2003;71:189-200.

102. Epstein DR, Dirksen SR. Randomized trial of a cognitive-behavioral intervention for insomnia in breast cancer survivors. Oncol Nurs Forum 2007;34:E51-9.

103. Dirksen SR, Epstein DR. Efficacy of an insomnia intervention on fatigue, mood and quality of life in breast cancer survivors. J Adv Nurs 2008;61:664-75.

104. Fiorentino L, McQuaid JR, Liu L, Natarajan L, He F, Cornejo M, et al. Individual cognitive behavioral therapy for insomnia in breast cancer survivors: a randomized controlled crossover pilot study. Nat Sci Sleep 2010;2:1-8

105. Garland SN, Carlson LE, Antle MC, Samuels C, Campbell T. I-CAN
SLEEP: rationale and design of a non-inferiority RCT of mindfulnessbased stress reduction and cognitive behavioral therapy for the treatment of insomnia in CANcer survivors. Contemp Clin Trials 2011;32: 747-54.

106. Fleming L, Randell K, Harvey CJ, Espie CA. Does cognitive behaviour therapy for insomnia reduce clinical levels of fatigue, anxiety and depression in cancer patients? Psychooncology 2014;23:679-84.

107. Matthews EE, Berger AM, Schmiege SJ, Cook PF, McCarthy MS, Moore CM, et al. Cognitive behavioral therapy for insomnia outcomes in women after primary breast cancer treatment: a randomized, controlled trial. Oncol Nurs Forum 2014;41:241-53.

108. Garland SN, Rouleau CR, Campbell T, Samuels C, Carlson LE. The comparative impact of mindfulness-based cancer recovery (MBCR) and cognitive behavior therapy for insomnia (CBT-I) on sleep and mindfulness in cancer patients. Explore (NY) 2015;11:445-54.

109. Casault L, Savard J, Ivers H, Savard MH. A randomized-controlled trial of an early minimal cognitive-behavioural therapy for insomnia comorbid with cancer. Behav Res Ther 2015;67:45-54.

110. Roscoe JA, Garland SN, Heckler CE, Perlis ML, Peoples AR, Shayne $\mathrm{M}$, et al. Randomized placebo-controlled trial of cognitive behavioral therapy and armodafinil for insomnia after cancer treatment. J Clin Oncol 2015;33:165-71.

111. Garland SN, Gehrman P, Barg FK, Xie SX, Mao JJ. CHoosing Options for Insomnia in Cancer Effectively (CHOICE): design of a patient centered comparative effectiveness trial of acupuncture and cognitive behavior therapy for insomnia. Contemp Clin Trials 2016;47:349-55.

112. Heckler CE, Garland SN, Peoples AR, Perlis ML, Shayne M, Morrow GR, et al. Cognitive behavioral therapy for insomnia, but not armodafinil, improves fatigue in cancer survivors with insomnia: a randomized placebo-controlled trial. Support Care Cancer 2016;24:205966.

113. Kamen C, Garland SN, Heckler CE, Peoples AR, Kleckner IR, Cole CL, et al. Social support, insomnia, and adherence to cognitive behavioral therapy for insomnia after cancer treatment. Behav Sleep Med 2017:1-13.

114. Peoples AR, Garland SN, Perlis ML, Savard J, Heckler CE, Kamen CS, et al. Effects of cognitive behavioral therapy for insomnia and armodafinil on quality of life in cancer survivors: a randomized placebo-controlled trial. J Cancer Surviv 2017;11:401-9.

115. Chung S, Youn S. The optimizing strategies for prescription of sleeping pills for insomnia patients. Sleep Med Res 2017;8:8-16.

116. Chung S, Youn S, Yi K, Park B, Lee S. Sleeping pill administration time and patient subjective satisfaction. J Clin Sleep Med 2016;12:5762. 